\title{
LA SIBIL·LA TIBURTINA, PERSONATGE DEL TEATRE MEDIEVAL
}

\author{
Francesc Massip \\ Universitat Rovira i Virgili \\ francesc.massip@urv.cat
}

En els darrers mesos he realitzat un exhaustiu estudi sobre el personatge de la Sibil.la Tiburtina com a rol escènic en el teatre català de l'Edat Mitjana i el Renaixement, així com les seves pervivències tradicionals en el teatre popular mallorquí.

L'objectiu era definir el paper d'aquella Sibil.la que vaticina a l'Emperador Octavi August l'adveniment del Messies, amb les distintes maneres de plantejar el diàleg entre tots dos personatges, el contrast dramàtic que això suposa i la lectura política que se'n deriva. I, a més a més, la ulterior evolució del personatge, quan s'acaba identificant l'Emperador amb Herodes i la cosa desemboca en un combat bé-mal que s'accentua amb tints paròdics en el terreny tradicional. Tot plegat posat en adequada comparació amb el teatre europeu tardomedieval (francès, italià, espanyol i anglès), que presenta fesomies similars o divergents.

En català es conserven dos textos del s. XV i almenys un del s. XVI, que són els següents:

- Rol de Sibil.la (d'una Representació de Sibil.la amb l'Emperador), Ms. IoI, fol. Ir., Biblioteca Universitària de Barcelona, text que presenta una primera fase de desenvolupament dramàtic que situem a començos del segle Xv.

- Lo fet de la Sibila e de l'Emperador Sèsar en les matinas de Nadal procedent de Sant Bartomeu del Grau (Osona), Ms. I494, fol. 2IV-26. Biblioteca de Catalunya. Peça dialogada que, cap a les acaballes del segle xv, presenta una decidida evolució dels personatges cap a la confrontació oberta i de rerefons polític.

- Consueta de la Nit de Nadal ( $\mathrm{n}^{\circ}$ I) de Mallorca, Ms. II39, Biblioteca de Catalunya. Es tracta d'un text probablement representat a la Catedral mallorquina i, per tant, molt més contingut en l'exposició del contrast dramàtic entre personatges, amb un emperador més humil i sofert.

En francès, hem localitzat peces o escenes similars tant al Mystère de l'Incarnation et Nativité de nostre Sauveur et Redempteur Jesus-Christ, Rouen 1474 (ed. Le Verdier I884-I886), com al Mystère de la Passion de Semur (I488) (ed. Roy 1974) i a Le Mistère du Viel Testament, París, c. I506-8 (ed. De Rothschild i Picot I878-189I), 
on hi ha inclòs el Mistère de Octovien et de Sibille Tiburtine, touchant la conception. Però particularment cal tenir en compte la peça Octavien et la Sibylle, carruatge número 69 de la processó de Lille (ed. Knight 20Io) i la tardana Nativité d'Huy (s. XVII) (ed. Thomas-Bourgeois I932), on apareix explícitament la identificació de l'Emperador amb Herodes. A més a més hem localitzat a la BnF tres manuscrits inèdits que incorporen la seqüència: els Dicts sibyllins en personnages, entre I515I53I; la Procession de Sibylles et de Prophètes, de principis del s. XvI, i la Passion de Valenciennes de 1547 .

En italià, l'escena s'inclou a La Passione di Revello, sacra rappresentazione quattrocentesca di ignoto piemontese (ed. Cornagliotti 1976) i a distintes representacions recollides per Vicenzo De Bartholomaeis (Laude drammatiche e rappresentazioni sacre, I943), Alessandro D’Ancona (Sacre rappresentazione dei secoli XIV, XV e XVI, 1872) i Nerida Newbigin (Nuovo corpus di Sacre Rappresentazioni fiorentine del Quatroccento, 1983). En anglès apareix al Chester Mystery Cycle (ed. Lumiansky i Mills 1974) i també al Wakefield Cycle of Mystery Plays (ed. Rose 196I).

He fet, doncs, una precisa discriminació del personatge sibil.lí i el seu contrast amb el representant del poder, sovint implícitament posat en relació amb els poders laics vigents. En el cas dels textos catalans podem pensar en sengles correlats amb Alfons el Magnànim i Joan II (o Ferran el Catòlic). A més a més, he demostrat com la llegenda romana de l'“Ara Coeli", que refereix el vaticini que va fer la Sibil.la Tiburtina a l'emperador Cèsar August (Octavià), va donar nom a una màquina aèria usada en el teatre medieval, primer per visualitzar l'aparició d'una verge amb un nen que mostra Sibil.la, després reutilitzada per a altres enginys voladors en les representacions que ho requerien. S'ha analitzat el recorregut d'aquesta tramoia des dels orígens medievals fins a l'explosió Barroca i les pervivències actuals.

Els resultats d'aquesta recerca s'han presentat al I Convegno Internazionale (Centro per la Ricerca sul Teatro Medievale, CRTM). Oggetti materiali e pratiche della rappresentazione nel teatro medievale, Università degli Studi di Genova, 2O-2I-22 de juny 2OI2, i al XVI Col-loqui de Llengua i Literatura Catalanes (AILLC), Universitat de Salamanca, I-6 de juliol 2012.

\section{REFERÈNCIES}

Chester Mystery Cycle, The, ed. R. M. Lumiansky i D. Mills, Chapel Hill i Londres, 1974.

D’Ancona, A. (ed.), Sacre rappresentazione dei secoli XIV, XV e XVI, Florència, I872. 
De Bartholomaeis, V. (ed.), Laude drammatiche e rappresentazioni sacre, Florència, 1943.

Mystère de l'incarnation et nativité de nostre Sauveur et Redempteur Jesus-Christ, Le, ed. P. Le Verdier, Rouen, i884-I886.

Mystère du Viel Testament, Le, ed. J. De Rothschild i E. Picot, París, I878-I89i. Mystères de la procession de Lille, Les, ed. A. Knight, Ginebra, 20 o.

Passione di Revello, La. Sacra rappresentazione quattrocentesca di ignoto piemontese, ed. A. Cornagliotti, Torí, 1976.

Newbigin, N. (ed.), Nuovo corpus di sacre rappresentazioni fiorentine del Quatroccento: edite e inedite tratte da manoscritti coevi o ricontrollate su di essi, Bolònia, 1983.

Roy, É., Le mystère de la Passion en France du XIV au XVI siècle. Étude sur les sources et le classement des mystères de la Passion, Ginebra, 1974.

Thomas-Bourgeois, C. A., "Le drame réligieux au pays de Liège, avec documents inédits", a Études de dialectologie romane dédiées a la mémoire de Charles Grandgagnage, París, 1932, pp. 283-313.

Wakefield Cycle of Mystery Plays, The, ed. M. Rose, Londres, I96r. 